\title{
O MODELO FEDERAL DO PROCESSO LEGISLATIVO E SUA OBSERVÂNCIA PELOS ESTADOS-MEMBROS.
}

\author{
Cláudio luis neves Castellano*
}

Assunto bastante tormentoso, e que não se encontra definitivamente esclarecido, diz respeito à obrigatoriedade dos Estados-membros reproduzirem o modelo do processo legislativo, tal como disposto na Constituição Federal.

A questão envolve, principalmente, o sistema federativo adotado em nosso país, cujos contornos, muitas vezes sutis, demandam melhor delineamento, cabendo esta tarefa ao Supremo Tribunal Federal.

Somente depois de a Suprema Corte julgar de modo definitivo as ações diretas de inconstitucionalidade sobre o tema, é que será possível divisar, com maior clareza, o que é obrigatório e o que não é obrigatório para os Estados-membros, isto é, quais os princípios do processo legislativo federal que devem ser observados pelas unidades federadas.

O ponto de tensão do modelo federativo brasileiro é o artigo 25 da Carta Federal, cujo teor é o seguinte: "Os Estados organizam-se e regem-se pelas Constituições e leis que adotarem, observados os princípios desta Constituição." É outorgada autonomia aos Estados (poder de auto-organização) e, simultaneamente, a organização estadual não poderá divergir dos princípios constantes da Constituição Federal. Vale dizer: trata-se de autonomia que somente subsiste dentro de certos parâmetros, conforme o balizamento imposto pelo modelo federal.

A tarefa crucial é identificar esses princípios, que exigem reprodução obrigatória, não comportando inovação pelos Estados-membros.

Embora o Supremo Tribunal Federal já tenha proferido julgamentos definitivos sobre o tema (1), é certo que existem inúmeras outras ações em tramitação funda-

* O autor é advogado. Foi Procurador-Chefe da Procuradoria Judicial da Assembléia Legislativa do Estado de São Paulo e atualmente é assessor da Secretaria Geral Parlamentar, daquela mesma Casa Legislativa.

\begin{tabular}{lll}
\hline R. Dir. Adm., & Rio de Janeiro, 216:57-63, & abr./jun. 1999 \\
\hline
\end{tabular}


mentadas na não conformidade da norma estadual ao texto da Constituição da República. no caso específico do processo legislativo.

Em sede liminar, a Suprema Corte tem suspendido sistematicamente a eficácia de leis e dispositivos constitucionais dos Estados, por não respeitarem a reserva de iniciativa inscrita no artigo $61, \S 1^{\underline{0}}$ da Carta Magna, que especifica quais as matérias que só podem ser normatizadas por iniciativa privativa do Presidente da República. Os julgamentos definitivos (cerca de uma dezena) assentam-se basicamente nessa mesma premissa.

No Estado de São Paulo, tais matérias, de iniciativa privativa do Governador, vêm elencadas no artigo $24, \S 2^{\circ}$ da sua Constituição, e tal como no modelo Federal, dizem respeito, fundamentalmente, à estrutura da administração pública e seus agentes.

A título de sinalização, contudo, é importante observar o que assentou o Supremo Tribunal Federal, ao julgar o pedido de liminar na ADIn n² 216-PB:

"O perfil da Federação brasileira, redefinido pela Constituição de 1988, embora aclamado por atribuir maior grau de autonomia aos Estados-membros, é visto com reserva por alguns doutrinadores, que consideram persistir no Brasil um federalismo ainda afetado por excessiva centralização espacial do poder em torno da União Federal.

Se é certo que a nova Carta Política contempla um elenco menos abrangente de princípios constitucionais sensíveis, a denotar, com isso, a expansão de poderes jurídicos na esfera das coletividades autônomas locais, o mesmo não se pode afirmar quanto aos princípios constitucionais extensíveis e aos princípios constitucionais estabelecidos, os quais, embora disseminados pelo texto constitucional, posto que não é tópica a sua localização, configuram acervo expressivo de limitações dessa autonomia local, cuja identificação — até mesmo pelos efeitos restritivos que deles decorrem - impõe-se realizar.

A questão da necessária observância, ou não, pelos Estados-membros, das normas e princípios inerentes ao processo legislativo, provoca a discussão sobre o alcance do poder jurídico da União Federal de impor, ou não, às demais pessoas estatais que integram a estrutura da Federação, o respeito incondicional a padrões heterônomos por ele próprio instituídos como fatores de compulsória aplicação.

Esse tema, que se revela essencial à organização político-administrativa do Estado brasileiro, ainda não foi decidido pelo Supremo Tribunal Federal. Da resolução dessa questão central emergirá a definição do modelo de Federação a ser efetivamente observado nas práticas institucionais.

Enquanto não sobrevier esse pronunciamento, impõe-se como medida de cautela a suspensāo liminar de preceitos inscritos em Constituições estaduais, que não hajam observado os padrões jurídicos federais, de extração constitucional, concernentes ao processo legislativo." (2).

Vê-se portanto que, apesar das liminares concedidas, o pronunciamento definitivo da Suprema Corte pode abrandar o rigor demonstrado até o momento, ao suspender cautelarmente quase todas as normas perante ela questionadas.

Vale anotar também a manifestação do Min. Celso de Mello, ao relatar o pedido de liminar na ADIn no 1434-SP: 
“- O modelo estruturador do processo legislativo, tal como delineado em seus aspectos fundamentais pela Constituição da República - inclusive no que se refere às hipóteses de iniciativa do processo de formação das leis - impõe-se, enquanto padrão normativo de compulsório atendimento, à incondicional observância dos Estados-membros. Precedentes: RTJ 146/388 - RTJ 150/482.

A jurisprudência dessa Suprema Corte já deixou assentado definitivamente que 'as regras básicas do processo legislativo federal - incluídas as de reserva de iniciativa - são de absorção compulsória pelos Estados, na medida em que substantivam prisma relevante do princípio sensível da separação e independência dos poderes' (ementa do julgamento definitivo da ADIn no 430-1-DF, j. 25.5.94, que invoca o decidido em sede de liminar na ADIn $n^{2} 822$, j. 5.2.93)." (3)

Além da reserva de iniciativa, o Supremo Tribunal Federal identificou, também, como princípio de reprodução obrigatória, o que diz respeito aos limites do poder de emenda parlamentar, enfatizando que os Estados-membros estão sujeitos à observância "das linhas básicas do modelo federal do processo legislativo, em particular, das que dizem com as hipóteses de iniciativa reservada e com os limites do poder de emenda parlamentar ..." (4)

Entretanto, ao mencionarem "modelo estruturador" e "regras básicas" do processo legislativo federal, os precedentes do STF permitem concluir que apenas as linhas básicas do processo legislativo exigem reprodução obrigatória, estando identificado, até o momento, um núcleo que diz respeito à iniciativa reservada e aos limites do poder de emenda parlamentar, núcleo esse relacionado diretamente com o princípio da separação dos Poderes.

Oportuno, em reforço de argumento, valer-se da doutrina do prof. Manoel Gonçalves Ferreira Filho:

"As regras estabelecidas para o processo legislativo no plano federal já não são obrigatórias para os Estados federados. Não há na Constituição em vigor norma equivalente ao art. 200 da Emenda $n^{0} 1 / 69$, o qual incorporava, no que coubesse, ao Direito Constitucional estadual as disposições constantes da Lei Magna federal. Ora, por julgamento unânime da doutrina e da jurisprudência, um dos pontos em que essa incorporação cabia era exatamente o processo legislativo, 'ex vi' do art. 13, III, da Emenda $\mathrm{n}^{0} 1 / 69$.

Mas, de qualquer forma, o art. 25 da Carta vigente manda os Estados, ao organizarem-se, observarem os princípios do ordenamento federal. Por isso, é de se perguntar se há princípios que se impõem ao Direito Constitucional, no que tange ao processo legislativo.

Não há dúvida que os Estados têm hoje, quanto ao processo legislativo, amplo campo de autodeterminação. Não estão obrigados a incorporar ao seu Direito normas específicas do Direito Federal. Apenas devem respeitar princípios - normas abstratas e genéricas - que se possam deduzir do processo legislativo federal $e$ que sejam suficientemente relevantes para que se justifique a sua obrigatoriedade.

É difícil e delicado identificar esses princípios. 
Parece. todavia, que um deles concerne à estrutura do processo legislativo ordinário: fase constitutiva integrada pela deliberação parlamentar mais sanção por parte do Chefe do Executivo, ou superação desta, por maioria qualificada.

Outro, à previsão de leis complementares sobre matérias especiais, análogas àquelas que a Constituição Federal prevê.

Terceiro, o da reserva da iniciativa em termos também análogos a essa Carta.

Mais discutível já é a possibilidade de legislação delegada.

De modo algum, porém, a admissão de medida provisória com força de lei, que é uma exceção (e aberrante) ao próprio sistema da Constituição brasileira." (5)

Quanto às medidas provisórias, o assunto gera opiniões divergentes entre os juristas. Como visto acima, o Prof. Manoel Gonçalves Ferreira Filho nega a possibilidade dos Estados instituírem-na.

Entretanto, em excelente trabalho sobre o tema, a Prof ${ }^{a}$ Regina Marta Macedo Nery Ferrari (6) entende cabível a adoção de medidas provisórias pelas unidades federadas, elencando a posição de vários doutrinadores, pró e contra.

Merece transcrição o seguinte trecho:

"A atual CF de 1988 não proíbe que os Estados e municípios adotem as medidas provisórias, o que possibilita sua previsão em Constituições estaduais e Leis Orgânicas Municipais. Entretanto, é necessário reconhecer que, como instrumento legislativo excepcional, se presta mais a dispor sobre matérias de competência da União, porém, nada impede que seus poderes constituintes decorrentes disciplinem a possibilidade de sua edição, dentro das competências que lhes são próprias, desde que sejam respeitados os princípios e limites que cercam as Medidas Provisórias Federais.

$\mathrm{O}$ prof. Clèmerson Merlin Clève observa que a competência dos Estados-membros e Municípios, na Constituição de 1988, é infima. "Daí porque adotando as medidas provisórias, os legislativos estaduais e municipais restariam ainda mais esvaziados". Assim, "Cumpre lembrar, entretanto, que os Constituintes Estaduais e os Legisladores Orgânicos Municipais, ao que consta, não se deixaram seduzir pela inexistência de vedação à adoção da MP. Tanto que, salvo exceções, preferiram não contemplar nas respectivas Cartas Políticas Estaduais e Municipais essa extraordinária espécie legislativa" (Clève, Clèmerson Merlin. As medidas provisórias e a Constituição Federal/88. Curitiba, Juruá: 1991, p. 94-95).

José Nilo de Castro e Hely Lopes Meirelles, embora reconhecendo a não-vedação constitucional, não aconselham a adoção de Medidas Provisórias em âmbito municipal (Direito Municipal Positivo, Belo Horizonte: Del Rey, 1991, p. 104 e Direito Municipal Brasileiro, São Paulo: Malheiros, 1991, p. 484, respectivamente).

José Afonso da Silva por sua vez, tratando do assunto, pergunta: "podem as Constituições estaduais instituí-las? $\mathrm{Na}$ edição anterior, respondemos que nada justificava sua existência no âmbito estadual, mas não víamos proibição em que o fizesse. Até onde sabemos, os Estados (e também Municípios) evitaram adotá-las. E hoje, 're melius propensa', achamos ponderável o argumento de que sendo exceção ao princípio da divisão de poderes, só valem nos limites estritos em que foram elas previstas na Constituição Federal, ou seja, apenas no âmbito federal, não se legitimando seu acolhimento nos Estados nem nos Municípios" (Curso de Direito Constitucional Positivo. São Paulo: Malheiros, 1994. p. 533). 
Por sua vez. em sentido contrário, Roque Carraza defende: "nada impede, porém. que, exercitando seus poderes constituintes decorrentes, os Estados. Municípios e o Distrito Federal prevejam a edição de medidas provisórias, respectivamente, estaduais, municipais e distritais. A elas, 'mutatis mutandis', devem ser aplicados os princípios e limitaçōes que cercam as medidas provisórias federais" (Curso de Direito Constitucional Tributário. $3^{\mathbf{a}}$ ed., São Paulo: RT, 1991.p. 172-173).

Considero que tem razão o Prof. Roque Carraza, pois a importância da admissão deste instrumento normativo na esfera estadual e municipal, repousa, primeiramente, no respeito à previsão constitucional, que admitindo campo próprio para sua atuação, determina a autonomia estadual, municipal e distrital: em segundo lugar, é forçoso reconhecer que podem existir situações imprevisíveis, que podem reclamar uma disciplina normativa excepcional, que por sua natureza urgente e emergencial deve estar incluída entre as competências do Chefe do Executivo, devendo para perder seu caráter temporário, ter a aprovação do Legislativo. Porém seu uso deve ser disciplinado de forma a impedir que venha a descaracterizar os pressupostos previstos constitucionalmente para sua admissão, isto é, a relevância e a urgência da matéria tratada."

Interessante notar que, mesmo aqueles que admitem a possibilidade dos Estados utilizarem-se das medidas provisórias, não recomendam a sua adoção ou, ainda reconhecendo a sua necessidade, advertem que o seu uso deve ser parcimonioso, dentro dos estritos limites de seus pressupostos (relevância e urgência da matéria) visto tratar-se, à unanimidade, de espécie legislativa excepcional.

Demonstrando, a final, que as medidas provisórias não despertaram o interesse dos Estados, o mesmo estudo da Prof ${ }^{\mathbf{a}}$ Regina Maria Macedo Nery Ferrari, informa que apenas Piauí (arts. 73, V e 75, $\S 3^{9}$ ); Tocantins (arts. 25 e 27); Acre (arts. 52 e 79) e Santa Catarina (arts. 48 e 51 ) inseriram em suas Constituições a previsão de medidas provisórias.

Acrescente-se ainda que o Supremo Tribunal Federal admitiu, em tese, a constitucionalidade de medidas provisórias estaduais (7).

Ao analisar a $A D N / n$ № 425-TO, a Suprema Corte suspendeu cautelarmente os efeitos das medidas provisórias $\mathrm{n}^{\mathrm{0}} \mathrm{s} 63$ e 65 do Estado de Tocantins. Entretanto, a liminar foi concedida diante do conteúdo normativo, e não pela espécie legislativa em si mesma.

Como se nota, o próprio Supremo Tribunal Federal e doutrinadores como o prof. Manoel Gonçalves Ferreira Filho apontam para a possibilidade de identificar-se um núcleo, um agrupamento de princípios basilares, cuja observância seria obrigatória para os Estados-membros. (8) Em contrapartida, há que se reconhecer também, a existência de uma margem, mesmo que estreita, de autonomia dos Estados, para disporem de forma inovadora, sobre alguns aspectos do procesiu legislativo, desde que não contrariem aqueles princípios fundamentais.

\section{Em conclusão}

- Como já acentuado pela doutrina e pela jurisprudência, os princípios norteadores do processo legislativo, cuja observância é obrigatória pelos Estados-membros, podem ser condensados nuclearmente. 
- A tarefa de identificar esses princípios fundamentais é bastante delicada. Embora já esboçada pela doutrina, e já iniciada pela jurisprudência, a identificação desses princípios ainda está a depender do julgamento definitivo do Supremo Tribunal Federal sobre as ações a ele submetidas (argüições incidentais e, principalmente, ações diretas de inconstitucionalidade). Somente após o desate dessas ações delinear-se-á, com clareza, a margem de autonomia que os Estados dispõem para eventuais inovações ou divergências do seu processo legislativo, em confronto com o modelo federal.

- De qualquer modo, é lícito afirmar, desde já, que essa margem de divergência existe, e pode subsistir, desde que não contrarie os princípios fundamentais constantes do modelo federal, cuja identificação demanda melhor aclaramento.

- Até o momento, no âmbito jurisprudencial, a Suprema Corte já identificou de modo claro e firme dois princípios fundamentais, de observância obrigatória: a reserva de iniciativa e os limites ao poder de emenda parlamentar.

citações

(1) - Algumas das ações julgadas pelo STF:

- ADIn $n^{\circ} 112-\mathrm{BA}$, Rel. Min. NÉRI DA SILVEIRA;

- ADIn no 120-AM. Rel. Min. MOREIRA ALVES;

- ADIn $n^{0} 1546-S P$, Rel. Min. NELSON JOBIM;

- ADIn n 152-MG, Rel. Min. ILMAR GALVÃO;

- ADIn $n^{2}$ 774-RS, Rel. Min. CELSO DE MELLO;

- ADIn no 430-DF

(2) - ADIn $n^{Q} 216-P B$, Rel. Min. CELSO DE MELLO

(Medida Liminar), j. 23.5.90, publ. in JSTF-LEX 180/52

(3) - ADIn $\mathrm{n}^{0}$ 1434-SP, Rel. Min. CELSO DE MELLO

(Medida Liminar) j. 29.8.96, publ. in JSTF-LEX 222/48

(4) - ADIn $n^{2} 822-$ RS, Rel. Min. SEPÚLVEDA PERTENCE

(Medida Liminar) publ. in RTJ 150/482

(5) - Prof. MANOEL GONÇALVES FERREIRA FILHO, "Do Processo Legislativo", Ed. Saraiva, $3^{\text {a }}$ ed., 1995, p. 244, g.n.

(6) - Prof REGINA MARIA MACEDO NERY FERRARI

"Medidas Provisórias - Estados e Municípios" em Cadernos de Direito Constitucional e Ciências Políticas, $n^{2} 19$, abril junho de 1997, Ed. RT, pgs 93 108.

(7) - ADIn n⿳0 425-TO em RDA 183/151

(8) - Alinhado aos precedentes do STF, o Órgão Especial do Tribunal de Justiça de São Paulo, ao julgar ADIns relativas a leis municipais, em confronto com a Constituição Estadual, firmou pacífico e reiterado entendimento de que "as regras sobre a organização interna das Casas Legislativas constituem princípios fundamentais de funcionamento do Poder Legislativo, de observância obrigatória nos Municípios." 
(ADIn no 30.758-0, Rel. Des. DANTE BUSANA, j. 16.10.96)

No mesmo sentido:

ADIn n 28.437-0, Rel. Des. DENSER DE SÁ, j. 04.9.96;

ADIn $n^{0} 31.290-0$, Rel. Des. VISEU JUNIOR, j. 18.9.96;

ADIn $n^{2}$ 31.974-0, Rel. Des. OETTERER GUEDES, j. 25.9.96;

ADIn n 20.894-0, Rel. Des. LUÍS DE MACEDO. 